\title{
Efectos de la Sentencia constitucional sobre la Ley del Suelo respecto de planes urbanísticos y sus actos de ejecución
}

\author{
Avelino Blasco Esteve \\ Catedrático de Derecho Administrativo \\ Universidad de las Islas Baleares
}

Sumario: I. CONSIDERACIONES GENERALES. II. EFECTOS SOBRE LOS PLANES URBANISTICOS: A) Planes en tramitación al publicarse la Sentencia B) Planes definitivamente aprobados, pero no firmes $C$ ) Planes definitivamente aprobados y firmes: - efectos producidos antes del 25 de abril, - efectos de estos Planes después del 25 de abril. III. EFECTOS SOBRE INSTRUMENTOS Y ACTOS DE EJECUCIÓN DEL PLANEAMIENTO: A) Procedimientos en tramitación al publicarse la Sentencia, B) Actos y medidas no firmes, C) Actos firmes: - actos que hayan sido confirmados por sentencias firmes, - restantes actos firmes.

\section{CONSIDERACIONES GENERALES}

La reciente STC 61/1997, de 20 de marzo, sobre el Texto Refundido de la Ley del Suelo de 1992 (TRLS), publicada en el BOE de 25 de abril, ha venido a suscitar numerosos interrogantes sobre su alcance y efectos respecto a los actos y normas que estuvieran basados en preceptos que hayan sido anulados por el Tribunal Constitucional. Nos referimos en concreto tanto a los Planes urbanísticos que se hayan dictado durante todos estos años en aplicación de preceptos anulados por la Sentencia, como a los instrumentos de ejecución del planeamiento (proyectos de compensación o reparcelación, etc.), o actos singulares (licencias, etc.) de intervención en el uso del suelo o de disciplina urbanística que apliquen preferentemente preceptos anulados.

Los datos legales a retener en este punto son conocidos: el art. 39 de la Ley Orgánica del Tribunal Constitucional (LOTC) señala que cuando la sentencia del Alto Tribunal declare la inconstitucionalidad de la ley «declarará igualmente la nulidad de los preceptos impugnados». El único límite que fija la propia LOTC a esta declaración consiste en que la misma no puede afectar a procesos fenecidos mediante sentencias con fuerza de cosa juzgada en los que se haya hecho aplicación de la ley inconstitucional, salvo en el caso de normas penales o sancionadoras en que, como consecuencia de la nulidad, pueda resultar una aplicación más favorable de la norma penal o sancionadora (art. 40.1). 
A partir de estos datos, el Tribunal Constitucional ha hecho tradicionalmente una aplicación más bien rígida de la regla de la nulidad, con un entendimiento «muy radical» de la consecuencia de eficacia ex tunc de la declaración de nulidad ${ }^{\prime}$. Sólo en algunas decisiones se ha apartado de esa consecuencia, aunque se trataba precisamente de supuestos especialmente importantes. En concreto, podemos citar las siguientes:

- la STC 60/1986, de 20 de mayo, que anuló determinados preceptos de un Decreto-Ley de medidas urgentes de reforma administrativa de 1982, señala en cuanto a las consecuencias de la anulación que ésta «no ha de comportar, sin embargo, la de los actos jurídicos dictados en ejecución de los preceptos que ahora se invalidan, ni, por lo mismo, la de las situaciones administrativas declaradas a su amparo»;

- de manera mucho más rotunda, la STC 45/1989, de 20 de febrero, sobre la Ley reguladora del Impuesto sobre la Renta de las Personas Físicas de 1978, se ha apartado también claramente del modelo tradicional, desvinculando la nulidad de la inconstitucionalidad y por ello declara inconstitucionales pero no nulos ciertos preceptos de la Ley impugnada. El Tribunal dedica todo un Fundamento Jurídico al tema (el 11. ${ }^{\circ}$ ) y afirma en esencia que

«ni esa vinculación entre inconstitucionalidad y nulidad es, sin embargo, siempre necesaria, ni los efectos de la nulidad en lo que toca al pasado vienen definidos por la Ley, que deja a este Tribunal la tarea de precisar su alcance en cada caso, dado que la categoría de la nulidad no tiene el mismo contenido en los distintos sectores del ordenamiento».

La tesis de esta STC ha sido reiterada en la STC 146/1994, de 9 de mayo, que declara inconstitucionales y nulos ciertos preceptos de varias leyes tributarias nacidas de la aplicación de la STC 45/1989;

- la STC 179/1994, de 16 de junio, resuelve diversas cuestiones de inconstitucionalidad sobre el Decreto-Ley de 26 de julio de 1929 y otras normas de rango legal, que establecían la adscripción obligatoria a las Cámaras de Comercio, Industria y Navegación, declara la insconstitucionalidad y nulidad de las normas impugnadas, pero en cuanto a los efectos y alcance del Fallo, el Tribunal señala expresamente que el mis-

1 F. Rubio Llorente, en «La jurisdioción constitucional como forma de creación del Derecho», Rev. Esp. de Derecho Constitucional, núm. 22 (1988), pág. 48. 
EFECTOS DE LA SENTENCIA CONSTITUCIONAL SOBRE LA LEY ...

mo no afecta a situaciones consolidadas derivadas de actos no impugnados en su momento:

«en tal sentido, debemos establecer que han de considerarse situaciones consolidadas no susceptibles de ser revisadas con fundamento en esta Sentencia, no sólo aquellas situaciones que hayan sido definitivamente decididas por resoluciones judiciales con fuerza de cosa juzgada (art. 40.1 LOTC), sino también, por exigencia del principio de seguridad jurídica (art. 9.3 CE), todas aquellas otras que no hubieren sido impugnadas en la fecha de publicación de esta Sentencia, es decir, tanto los pagos ya efectuados de cuotas no recurridas, como las devengadas y aún no pagadas, que no estén pendientes de reclamación o recurso administrativo o judicial interpuesto dentro de plazo antes de dicha fecha, a partir de la cual esta Sentencia producirá todos los efectos que le son propios».

A diferencia de estas sentencias, la STC sobre el TRLS declara nulos los preceptos inconstitucionales del Texto, sin efectuar precision alguna sobre el alcance de la declaración de nulidad, lo que constituye a mi juicio un defecto grave de la sentencia, dada la trascendencia práctica del tema. Ante una cuestión del calado de la que comentamos, me parece totalmente indispensable que el Tribunal debería haberse pronunciado sobre las enormes consecuencias de su declaración de inconstitucionalidad de numerosos preceptos de la ley urbanística básica. Lamentablemente no ha sido así, lo que provoca gran confusión sobre el alcance y efectos de la sentencia. Ello significa que, en última instancia, tendrán que ser los Tribunales Contencioso-Administrativos los que decidan la cuestión -si se les plantean recursos al respecto, como es previsible-, con lo que la solución al tema se trasladará de hecho del Alto Tribunal a los órganos judiciales ordinarios.

Entrando a determinar la solución de la cuestión planteada, conviene tener en cuenta de entrada dos observaciones importantes:

- en muchas (por ejemplo, disciplina urbanística), la mayoría de Comunidades Autónomas dispone de legislación propia, que será normalmente la que se habrá aplicado en los actos de intervención o de disciplina que se hayan dictado durante todos estos años pasados. Por lo tanto, la anulación de preceptos del TRLS no influirá por lo general en la cobertura jurídica de dichos actos, dado que se amparaban en la legislación autonómica sobre urbanismo;

- otras Comunidades (como Navarra o la Comunidad Valenciana) disponen de legislación urbanística general propia en el mismo sentido que 
el TRLS, por lo que esta legislación legitimará los Planes y actos de aplicación que se hayan dictado en esas Comunidades;

- por otra parte, la anulación de muchos preceptos del TRLS en estas materias hace volver a entrar en vigor la legislación urbanística anterior a la LRRU de 1990 (Ley del Suelo de 1976, Decretos-Leyes de 1980 y 1981), que tenía en muchas materias una regulación parecida o incluso similar a la que ahora se anula. Por ello, muchos de los actos que se hayan dictado encuentran seguramente cobertura en esa legislación anterior y en los reglamentos que la desarrollan, con lo que no se verán afectados por la declaración de nulidad.

En resumen, el problema se plantea sólo cuando una determinada norma o acto se hubiera basado exclusiva o principalmente en preceptos anulados por la sentencia constitucional, sin encontrar ninguna cobertura en la correspondiente legislación autonómica o en la legislación urbanística estatal anterior a 1990 o, en definitiva, en otras normas o principios que la legitimen al margen de la norma anulada (BELADIEZ Rojo) ${ }^{2}$. En este supuesto, podríamos plantearnos como posibles las siguientes hipótesis, respecto a aquellos actos y normas de aplicación:

- Efectos de la Sentencia sobre Planes urbanísticos:

- sobre Planes en tramitación;

- sobre Planes definitivamente aprobados, pero no firmes;

- sobre Planes definitivamente aprobados y firmes.

- Efectos sobre instrumentos y actos de ejecución o aplicación del planeamiento:

— sobre actos en tramitación;

- sobre actos definitivamente aprobados, pero no firmes;

- sobre actos definitivamente aprobados y firmes.

Este es entonces el esquema que vamos a abordar en la exposición que sigue.

2 M. Beladfez Rojo, Validez y eficacia de los actos administrativos, Ed. Marcial Pons, Madrid, 1994, pág. 335 y ss. 
EFECTOS DE LA SENTENCIA CONSTITUCIONAL, SOBRE LA LEY ..

\section{EFECTOS SOBRE PLANES URBANÍSTICOS}

Los efectos sobre Planes urbanísticos pueden ser muy variados, porque las situaciones de éstos pueden ser también muy dispares. De entrada, hay que señalar que nos referimos aquí a Planes adaptados al TRLS de 1992, ya que si no lo estuvieran, la Sentencia constitucional tiene incidencia alguna sobre los mismos.

\section{A) Planes en tramitación en el momento de publicarse la Sentencia}

\section{a) En cuanto a las normas procedimentales}

El principio tradicional de nuestro Derecho es el de que los procedimientos administrativos se rigen, en cuanto a su tramitación, por la normativa vigente en el momento en que se iniciaron. Este principio se encuentra recogido con carácter general en la Disposición Transitoria de la Ley de Procedimiento Administrativo Común de 1992 («A los procedimientos ya iniciados antes de la entrada en vigor de la presente Ley no les será de aplicación la misma, rigiéndose por la normativa anterior») y está recogida también - para el ámbito urbanístico- en la Disposición Transitoria de la Ley 7/1989 ( «A los procedimientos ya iniciados antes de la entrada en vigor de la presente Ley no les será de aplicación lo dispuesto en los artículos 1,3 y 4 del mismo, rigiéndose por la normativa anterior»).

En consecuencia, creo que los procedimientos de tramitación de planes urbanísticos pueden seguir realizándose con arreglo a los preceptos procedimentales anulados del TRLS, aunque debe reconocerse inmediatamente que esta precisión tiene poca trascendencia a efectos prácticos, porque el TRLS es sustancialmente idéntico a la legislación estatal anterior a 1990 en lo que respecta a la tramitación de Planes.

\section{b) En cuanto a las normas materiales o de fondo}

En este caso parece clara la inaplicabilidad de los preceptos anulados por la Sentencia con posterioridad al día de su publicación, ya que las aprobaciones que se efectúen habrán de adaptarse necesariamente a la legislación vigente tras la Sentencia (la autonómica, si existe, y, en su defecto, la legislación estatal de 1976-1980-1981), lo que excluye la aplicación en dichos planes de los preceptos anulados. Ello se debe en suma a que el acto de aprobación definitiva de estos Planes se producirá después de publicada la Sentencia, por lo que 
REALA 273 (ENERO-ABRIL, 1997)

ésta habrá producido ya su efecto típico de expulsar la norma inconstitucional del ordenamiento jurídico.

La idea que se acaba de expresar se confirma en la STC 19/1987, de 17 de febrero, que declaraba inconstitucional y anulaba un precepto de la Ley 24/1983, de Medidas Urgentes sobre Haciendas Locales. Dicha Sentencia señala que:

«Declarada la inconstitucionalidad del art. 13.1 de la Ley 24/1983, los efectos de esta declaración no sólo han de incidir en el proceso judicial que está en la base del presente, sino que deben deparar también —en mérito de la nulidad que nuestra Ley Orgánica prescribe (art. 39.1) - la definitiva expulsión de aquella disposición de Ley del ordenamiento. En virtud de esta Sentencia, no podrán los Ayuntamientos actuar la libre potestad que en su favor creó el precepto declarado inconstitucional...».

También la citada STC 45/1989, sobre la Ley del IRPF, declara que:

«en lo que toca a los efectos, hemos de comenzar por recordar que, de acuerdo con lo dispuesto en la Ley Orgánica de este Tribunal (art. 39.1), las disposiciones consideradas inconstitucionales han de ser declaradas nulas, declaración que tiene efectos generales a partir de su publicación en el BOE (art. 38.1 LOTC) y que en cuanto comporta la inmediata y definitiva expulsión del ordenamiento de los preceptos afectados (STC 19/1987, f.j. 6..$^{\circ}$ impide la aplicación de los mismos desde el momento antes indicado, pues la Ley Orgánica no faculta a este Tribunal, a diferencia de lo que ocurre en algún otro sistema, para aplazar o diferir el momento de efectividad de la nulidad».

Más específicamente, la STC 128/1994, de 5 de mayo, que declara la nulidad de ciertos preceptos de una Ley de 1982 y un Decreto-Ley de 1928, que establecían privilegios ejecutivos a favor del Banco Hipotecario de España, se pronuncia sobre los efectos de la sentencia sobre los procesos prendientes, afirmando que:

«tratándose de una norma procesal como sucede en este caso es preciso, sin embargo, modular el alcance de esta resolución en los procesos en curso, para atender adecuadamente a otros valores con trascendencia constitucional, como los derechos de las partes presentes en el procedimiento, que se verían gravemente comprometidos por la desaparición del cauce procesal en que han de ejercitarse sus pretensiones. Ha de declararse en consecuencia, que los efectos de esta Sentencia en los procesos pendientes sólo se extenderán a los actos procesales que hayan de dictarse a partir de la publicación de la presente Sentencia, correspondiendo a los órganos judi- 
EFECTOS DE LA SENTENCLA CONSTTUUCIONAL SOBRE LA LEY ..

ciales competentes llevar a cabo las adaptaciones procesales que estimen necesarias».

Esta conclusión implicará de hecho la necesidad de adaptar los Planes que se estén tramitando en abril de 1997 a la legislación autonómica o estatal antes citada, depurándolos de referencias a preceptos anulados del TRLS.

\section{B) Planes definitivamente aprobados, pero no firmes}

Puede darse el caso de Planes que estén definitivamente aprobados en el momento de publicarse la Sentencia, pero que hayan sido recurridos en su momento, sin que se haya resuelto todavía el recurso correspondiente. ¿Cuál será la solución a adoptar por la sentencia judicial o resolución administrativa que se dicte?

En este punto es donde se plantean los problemas más complicados de resolver. Porque tenemos, por una parte, una serie de preceptos del TRLS que han sido anulados por inconstitucionales y, por otra, muchos Planes urbanísticos que han aplicado dichos preceptos, incorporando regulaciones directamente derivadas de los mismos.

Como regla de principio, podemos afirmar que la invalidez de la norma superior (la ley en este caso) se comunica a la norma inferior que la desarrolla (el reglamento), porque sería absurdo admitir como regla general que la norma inferior puede disponer válidamente lo que le está impedido a la norma de la que dimana. Ahora bien, este criterio puede sufrir importantes matizaciones en el caso de que la invalidez de la norma superior derive no de su contenido sino de razones formales o procedimentales: en este supuesto, la desaparición de la norma superior no lleva necesariamente a la invalidez de la norma inferior, porque ésta puede encontrar tal vez cobertura suficiente en la potestad normativa del órgano que la dicta o en otros principios generales, a tenor de las reglas generales de distribución normativa.

Todo ello significa que la anulación de un precepto legal comportará normalmente la invalidez sobrevenida del precepto reglamentario de aplicación: si un precepto legal contradice a la Constitución, también la norma reglamentaria que lo desarrolle la vulnerará en principio, con la consecuencia de nulidad de pleno derecho de ésta (art. 62.2 de la Ley de Procedimiento Administrativo Común). Pero en el caso de que aquella anulación se deba a motivos formales, el precepto reglamentario no es necesariamente ilegal sino que deberá ser confrontado con el resto del ordenamiento jurídico y, en especial, con las reglas generales de reparto normativo entre la ley y el reglamento, en especial del principio de reserva material de ley. Esto es lo que ocurre, a mi juicio, en el 
caso que nos ocupa: la anulación de los preceptos del TRLS se ha debido siempre a razones de forma (competenciales, concretamente) y no a razones de fondo, por lo que la anulación de aquellos preceptos no arrastra sin más la de los Planes que los apliquen.

Lo anterior significa que los Planes urbanísticos que han aplicado los preceptos legales anulados se van a encontrar en muchas ocasiones con falta de cobertura suficiente para imponer determinadas regulaciones (por ejemplo, en lo que respecta al quantum de las cesiones de aprovechamiento), dado que se trata de medidas que necesitaban una habilitación legal, al constituir materias reservadas a la ley: si el TRLS no proporciona cobertura válida a la cesión del $15 \%$ de aprovechamiento a la Administración (y tampoco existe ley autonómica que lo autorice), los Planes urbanísticos tampoco pueden disponer dicha cesión, al carecer de habilitación legal para ello. Pero otras veces, por el contrario, la desaparición del precepto correspondiente del TRLS no llevará a la invalidez consiguiente de los Planes que los hayan aplicado, porque la regulación de éstos podrá justificarse y ampararse en la potestad reglamentaria general del órgano que los aprob6 o en principios generales del ordenamiento ${ }^{3}$.

En consecuencia, ante cualquier problema en concreto que se plantee sobre la aplicabilidad de estos Planes, habrá que confrontar su regulación en el tema con el resto del ordenamiento jurídico, una vez eliminados del mismo los preceptos anulados del TRLS. Y sólo cuando no se encuentre cobertura suficiente a dicha regulación en otras normas de rango legal o en la propia potestad normativa de planeamiento, habrá que concluir en la invalidez de la normativa del Plan.

Desde un punto de vista práctico, y sin que podamos examinar todas las hipótesis posibles, podemos pensar entonces en dos grandes grupos:

1. Casos en que los Planes de que hablamos pierdan la legitimidad o cobertura de algunas de sus reglas y normas por la desaparición de los preceptos correspondientes del TRLS: aquí la invalidez de este Texto se comunica a aquellas reglas de los Planes, que dejan de ser aplicables a partir de la publicación de la sentencia. Por poner un ejemplo: tras la anulación del art. 30.1 y 3 (éste parcialmente) del TRLS, me parece evidente que ningún Ayuntamiento puede declarar - salvo que lo permita la legislación autonómica- la reducción del 50\% del aprovechamiento patrimonializable y la expropiación o venta forzosa de los terrenos por no haber solicitado la licencia en plazo, por mucho que su Plan de urbanismo haya recogido expresamente esta posibilidad; en este

3 Por ejemplo, J. M. MERelo Abela sostiene con detallada argumentación que la delimitación de áreas de reparto y la fijación de aprovechamientos tipo era ya posible con arreglo a la legislación anterior a 1990 (en Contenido y alcance de la Sentencia 61/1997, del Tribunal Constitucional sobre la Ley del Suelo. Ed. Praxis, Madrid, 1997, págs. 122 y ss.). 
caso, la anulación de aquellos preceptos del TRLS haría claramente inaplicables los correlativos preceptos del Plan.

En este supuesto considero inaplicables los preceptos anulados por la Sentencia para la resolución de los recursos administrativos o jurisdiccionales pendientes, en cuanto a las reglas de fondo: como dice el fragmento que se ha transcrito antes de la STC 45/1989, no es legalmente posible aplicar los preceptos anulados por una sentencia constitucional con posterioridad a la publicación de la misma. En la misma línea, la STC 179/1994 antes citada declara que a partir de la fecha de publicación de la Sentencia, ésta «producirá todos los efectos que le son propios", dando a entender claramente que se ha de aplicar necesariamente a la resolución de los recursos interpuestos contra cuotas de las Cámaras de Comercio, Industria y Navegación.

En consecuencia, el órgano administrativo o jurisdiccional que resuelva el correspondiente recurso no puede hacer uso de dichos preceptos al adoptar la decisión pertinente sobre el Plan impugnado, sino que deberá aplicar la normativa autonómica o, en su caso, la normativa estatal anterior a la LRRU de 1990, dado que éste es el Derecho urbanístico vigente tras la STC que comentamos.

2. Supuestos en que, a pesar de la anulación de los preceptos correspondientes del TRLS, la regulación del Plan en un tema determinado encuentra cobertura suficiente en otras normas legales o en la propia potestad de planeamiento urbanístico: aquí la regulación del Plan deberá considerarse conforme con el ordenamiento jurídico, por lo que no podrán hacerse reproches a su aplicabilidad.

Este sería, por ejemplo, el caso de la delimitación de áreas de reparto y fijación de aprovechamientos tipo, si se admite que estas técnicas encuentran apoyo y fundamentación suficiente en el conjunto del ordenamiento jurídico, al margen de los preceptos anulados del TRLS ${ }^{4}$.

\section{C) Planes definitivamente aprobados y firmes}

Nos referimos ahora al caso de los Planes urbanísticos dictados en aplicación de la LRRU y del TRLS y que no fueron impugnados en su día, en lo que se refiere a los preceptos y reglas de aquéllos que se basen exclusiva o principalmente en preceptos anulados por la STC, por lo que no encuentran cobertura ni en la legislación autonómica ni en la legislación estatal anterior a la LRRU de 1990 (por ejemplo, Planes que hayan incorporado la técnica de las

\footnotetext{
4 Véase la nota anterior. Bajo la vigencia de la LS76, el TS había considerado conforme a Derecho que los planes fijasen un aprovechamiento tipo en suelo urbano: STS de 20 de junio de 1989 (Arz. 4869).
} 
áreas de reparto y la determinación de los aprovechamientos tipo, en base a los arts. 94 a 99 TRLS - preceptos éstos que han sido íntegramente anulados-).

En esta hipótesis, me parece indispensable diferenciar la incidencia de la Sentencia sobre estos Planes, antes y después de publicarse aquélla (el 25 de abril de 1997).

\section{a) Efectos de estos Planes que se hayan producido antes del 25 de abril}

La aplicación de cualquier norma, como es un Plan de urbanismo, se concreta en los actos de aplicación que se dicten al amparo de la misma. En el caso de un Plan, esos actos pueden ser de muy distinto tipo: instrumentos de ejecución del Plan (Proyectos de compensación o reparcelación, Proyectos de urbanización, etc.); actos de intervención en la edificación o uso del suelo (licencias, órdenes de ejecución, etc.); medidas de restablecimiento de la legalidad urbanística (órdenes de demolición, etc.); sanciones administrativas, etc. Es obvio que la ejecución de estos Planes que ahora contemplamos habrá dado lugar con seguridad a que se hayan aprobado instrumentos de ejecución o dictado actos de aplicación antes de publicarse la Sentencia constitucional.

Por esa razón, la incidencia de la Sentencia sobre los Planes que sean firmes se reconduce al análisis de la legalidad y conservación de dichos instrumentos y actos de aplicación ya aprobados o dictados antes del 25 de abril, cuya situación puede ser a su vez muy distinta (dependiendo si son firmes o no lo son). Como este tema lo analizamos con detalle más adelante, en el apartado III, me remito ahora a lo que allí se expondrá.

\section{b) Efectos de estos Planes después del 25 de abril}

Aquí reitero las consideraciones ya efectuadas en el apartado B) (Planes definitivamente aprobados, pero no firmes), que entiendo perfectamente aplicables a este supuesto.

\section{EFECTOS SOBRE INSTRUMENTOS Y ACTOS DE EJECUCIÓN O APLICACIÓN DEL PLANEAMIENTO}

\section{A) Procedimientos que están en tramitación en el momento de publicarse la sentencia}

\section{a) En cuanto a las normas procedimentales}

Tenemos que repetir aquí lo que ya se ha dicho respecto a los Planes en tramitación: la tramitación de instrumentos de ejecución puede seguir realizándo- 
EFECTOS DE LA SENTENCIA CONSTITUCIONAL SOBRE LA LEY..

se con arreglo a los preceptos procedimentales anulados del TRLS. Esto significa, por ejemplo, que a mi juicio es lícito seguir tramitando un Proyecto de Compensación por el procedimiento abreviado del art. 161 del TRLS, a pesar de que este precepto ha sido anulado por la STC que comentamos.

\section{b) En cuanto a las normas sobre el fondo}

En este caso, me parece clara la inaplicabilidad de los preceptos anulados por la Sentencia desde el día de su publicación, ya que los proyectos que se aprueben y las resoluciones que se dicten habrán de adaptarse necesariamente a la legislación vigente tras la Sentencia, lo que excluye la aplicación de los preceptos anulados por ésta.

Ahora bien, la inaplicación de los preceptos anulados no comporta en todo caso la no utilización de las técnicas en ellos previstas, ya que éstas tal vez puedan ampararse en otras normas del Derecho urbanístico. Habrá que analizar, por ello, en cada caso si es posible encontrar cobertura normativa suficiente para esas técnicas.

\section{B) Actos y medidas no firmes (por haber sido recurridos en su momento)}

En este supuesto considero invocable en principio la misma regla que en el caso anterior, a saber, la inaplicabilidad de los preceptos anulados por la Sentencia tras su publicación, para la resolución de los recursos administrativos o jurisdiccionales formulados en su día. En consecuencia, el organo administrativo o jurisdicional que resuelva el correspondiente recurso no podrá hacer uso de dichos preceptos al adoptar la decisión pertinente, sino que deberá aplicar la normativa de la legislación estatal anterior a la LRRU de 1990 o, en su caso, la normativa autonómica, para decidir la legalidad del acto o Proyecto impugnado. Pensemos al respecto que, una vez eliminados del ordenamiento jurídico los preceptos del TRLS anulados por la sentencia constitucional, el acto impugnado puede encontrar cobertura en otros preceptos o principios del Derecho urbanístico.

Pongamos un ejemplo: un Proyecto de Compensación o Reparcelación en suelo urbano en el que se atribuya $15 \%$ del aprovechamiento urbanístico a la Administración (lógicamente, con anterioridad al Decreto-Ley 5/1996, que varía el quantum de las cesiones), Proyecto que fue impugnado en su día mediante el recurso pertinente. Pues bien, como la Sentencia constitucional anula tanto el art. 27.1 y 4 como la Disp. Trans. Primera, ap. 2, del TRLS - que eran los que establecían la atribución de aprovechamiento urbanístico a la Administración en el supuesto que comentamos-, el Tribunal contencioso o el organo administrativo que resuelvan el recurso de que se trate no podrán aplicar di- 
chos preceptos en su decisión, sino que tendrán que hacer uso en su lugar de la legislación estatal de 1976. Y como ésta no preveía esa atribución de aprovechamiento del $15 \%$ a la Administración, la consecuencia obligada será la de anular la cesión que comentamos al resolver el recurso de que se trate.

Esta conclusión no se modifica, en mi opinión, ni siquiera en el caso de que exista planeamiento general adaptado al TRLS que hubiera recogido en su texto el deber que comentamos, ya que al tratarse de una norma reglamentaria de desarrollo de una ley anulada, la eliminación de ésta comportará normalmente la ilegalidad implícita de aquélla en los preceptos correspondientes, como ya se ha dicho más atrás. La excepción a la conclusión a que hemos llegado vendrá constituida por el supuesto de que exista legislación autonómica que establezca ese mismo porcentaje de «cesión» (como ocurre, por ejemplo, en Navarra) y que la licencia de que hablamos se hubiera otorgado al amparo de esta legislación: aquí, la anulación de los preceptos del TRLS no afecta lógicamente a la ley autonómica ni a los actos dictados en su aplicación. En cambio, no varía la conclusión en el caso de que los actos recurridos hayan sido dictados bajo la vigencia y en aplicación de la LRRU de 1990 y no propiamente del TRLS de 1992 (de preceptos anulados del mismo, claro está), y ello porque, aunque la anulación se declare sólo de determinados preceptos del TRLS, me parece obvio que esa anulación conlleva la de los preceptos similares de la LRRU, al estar esta Ley refundida en el TRLS de 1992.

No obstante lo anterior, cabe en este punto introducir varios matices que modulan la conclusión anterior. Primero, el supuesto de que el acto o Proyecto impugnado derive de un convenio urbanístico, que legitime el contenido de aquél (por ejemplo, en cuanto a los porcentajes de aprovechamiento que se atribuyen a la Administración). Aquí, me parece lógico entender que la regla anterior cede ante la existencia de un negocio jurídico bilateral, en el que ambas partes han aceptado sus respectivas prestaciones. De todos modos, en esta hipótesis existe el problema subyacente de la causa del convenio, ya que el promotor/propietario puede alegar que al firmar el convenio se limitó simplemente a aceptar lo que era legal en aquel momento, porque no tenía otra alternativa posible.

Segundo, hay que pensar por un momento en otro supuesto posible: que la impugnación del acto o Proyecto se base exclusivamente en motivos de forma o procedimentales.

\section{C) Actos firmes}

Ante el silencio de la Sentencia constitucional, los mayores problemas se presentan con respecto a los actos firmes que no fueron recurridos en su momento. Con la LOTC en la mano, debemos distinguir dos supuestos diferentes: 
EFECTOS DE LA SENTENCIA CONSTTIUCIONAL SOBRE LA LEY ..

\section{a) Actos que hayan sido confirmados por sentencias firmes}

En esta hipótesis, el art. 40.1 LOTC declara la inmodificabilidad de las situaciones creadas por dichas sentencias, al gozar de fuerza de cosa juzgada, salvo en el caso de ciertos procedimientos sancionadores: «Las sentencias declaratorias de la inconstitucionalidad de Leyes ... no permitirán revisar procesos fenecidos mediante sentencia con fuerza de cosa juzgada en los que se haya hecho aplicación de las Leyes ... inconstitucionales, salvo en el caso de los procesos penales o contencioso-administrativos referentes a un procedimiento sancionador en que, como consecuencia de la nulidad de la norma aplicada, resulte una reducción de la pena o de la sanción o una exclusión, exención o limitación de la responsabilidad».

Por consiguiente, no hay posibilidad de revisar los actos administrativos que hayan sido confirmados por sentencias firmes, con la única excepción de los actos de naturaleza sancionadora en que se pueda hacer aplicación del inciso final del precepto.

\section{b) Restantes actos firmes}

Nos referimos ahora a actos administrativos que no fueron recurridos en su momento, por lo que han devenido actos firmes, en su modalidad de consentidos. Como es lógico, contra estos actos ya no cabrá recurso alguno, pero el problema es si se puede pedir la revisión de oficio de los mismos, en base a su posible nulidad (art. 102 de la Ley de Procedimiento Administrativo Común) o anulabilidad (art. 103 de la misma Ley).

En este punto se presentan notables dudas sobre los efectos de la sentencia, ya que el silencio de la misma al respecto podría ser interpretado razonablemente como indicativo de que hay que aplicar sin más los efectos generales de la declaración de inconstitucionalidad de las leyes (art. 39.1 LOTC) y que la nulidad de la norma arrastra también la nulidad de sus actos de aplicación, pudiendo éstos ser revisados en su caso, atribuyéndole a aquella nulidad efectos ex tunc. Esta tesis supondría - de ser correcta - nada menos que la posibilidad de pedir y obtener la revisión de oficio de aquellos actos urbanísticos firmes basados exclusivamente en preceptos anulados (por ejemplo, un proyecto de compensación o reparcelación en el que se hayan efectuado cesiones del $15 \%$ de aprovechamiento tipo o medio, al menos en lo que se refiere a esta cesión).

A mi juicio, esa tesis no es correcta, a pesar de la falta de pronunciamiento de la sentencia al respecto, porque entiendo que los actos administrativos firmes dictados en aplicación de los preceptos anulados así como las situaciones 
jurídicas a que han dado lugar deben mantenerse sin modificaciones. Los argumentos para ello son varios y han sido recogidos más o menos explícitamente por las SSTC antes citadas. Esos argumentos pueden ser sistematizados como sigue:

1. La aplicación del principio de seguridad jurídica (art. 9.3 CE) lleva a impedir la remoción de actos administrativos firmes en un caso como éste en que la tesis contraria comportaría unas consecuencias desorganizativas de enorme calibre en el orden práctico. Este argumento ya había sido destacado por la doctrina alemana (evitar el «caos») ${ }^{5}$ y había sido utilizado por la jurisprudencia del Tribunal de Justicia de las Comunidades Europeas (sentencia Defrenne, de 8 de abril de 1976), así como por el Tribunal Europeo de Derechos Humanos (sentencia Markx, de 13 de junio de 1989) ${ }^{6}$. La primera de ellas señala expresamente que «consecuencias imperiosas de seguridad jurídica que se refieren al conjunto de los intereses en juego, tanto públicos como privados, impiden en principio poner en cuestión las remuneraciones referentes a períodos pasados».

Pues bien, nuestro Tribunal Constitucional ha hecho uso de este mismo argumento en la citada Sentencia 45/1989, en relación con las declaraciones de la renta anteriores a la publicación de la sentencia: «entre las situaciones consolidadas que han de considerarse no susceptibles de ser revisadas como consecuencia de la nulidad que ahora declaramos figuran no sólo aquéllas decididas mediante sentencia con fuerza de cosa juzgada (art. 40.1 LOTC), sino también, por exigencia del principio de seguridad jurídica (art. 9.3 CE), las establecidas mediante las actuaciones administrativas firmes». El mismo criterio se emplea en la STC 179/1994: «han de considerarse situaciones consolidadas no susceptibles de ser revisadas con fundamento en esta Sentencia, no sólo aquellas situaciones que hayan sido definitivamente decididas por resoluciones judiciales con fuerza de cosa juzgada (art. 40.1 LOTC), sino también, por exigencia del principio de seguridad juridica (art. 9.3 CE), todas aquellas otras que no hubieren sido impugnadas en la fecha de publicación de esta Sentencia».

5 Véase el resumen que de la misma hace R. BOCANEGRA SIERRA en «Sobre el alcance objetivo de las sentencias del Tribunal Constitucional», en el Libro Homenaje al Prof. E. García de Enterria, Ed. Civitas, Madrid, 1991, vol. I, pág. 528. Esa doctrina considera que se trata de evitar la creación de un vacío normativo sobre una determinada materia en caso de declarar la nulidad de la norma (evitar el «caos»).

6 Sentencias comentadas elogiosamente por E. GARCtA DE ENTERRta en «Un paso importante para el desarrollo de nuestra justicia constitucional: la doctrina prospectiva en la declaración de ineficacia de las Leyes Constitucionales», REDA 61 (1989), págs. 7 y 8 . Se puede encontrar la referencia de más sentencias del TJCE en el trabajo de R. ALONSo GARCIA, «El Tribunal Constitucional y la eficacia temporal de sus sentencias anulatorias», RAP 119 (1989), pág. 265. 
EFECTOS DE LA SENTENCIA CONSTMUCIONAL SOBRE LA LEY ..

También la STC 146/1994, de 9 de mayo, que declara inconstitucionales y nulos ciertos preceptos tributarios derivados de la aplicación de la STC 45/1989, vuelve a la misma idea:

«En lo que toca a los efectos de esta Sentencia ..., debemos establecer que las situaciones consolidadas, sea mediante Sentencia firme (art. 40.1 LOTC) o por actuaciones administrativas firmes (art. 9.3 CE) no son susceptibles de ser revisadas como consecuencia de la nulidad que declaramos, la cual no podrá justificar una pretensión de devolución de ingresos indebidos».

2. Los preceptos anulados forman parte de un sistema o conjunto de normas y reglas, en el que otras piezas del mismo no han sido afectadas por la Sentencia; pues bien, la mera declaración de nulidad de algunas piezas del sistema no tiene virtualidad para reordenar el régimen urbanístico en su conjunto. Este es otro de los argumentos que emplea la STC 45/1989 para justificar la aplicación meramente prospectiva o pro futuro de la declaración de inconstitucionalidad que efectúa: «... los preceptos de la Ley 44/1978 declarados inconstitucionales formaban parte de un sistema legal cuya plena acomodación a la Constitución no puede alcanzarse mediante la sola anulación de aquellas reglas, pues la sanción de nulidad, como medida estrictamente negativa, es manifiestamente incapaz para reordenar el régimen del Impuesto sobre la Renta de las Personas Físicas en términos compatibles con la Constitución». A este respecto, el Tribunal pone de manifiesto que «otras piezas del sistema legal ... no han sido afectadas por el fallo de inconstitucionalidad y permanecen, por consiguiente, en vigor».

A mi juicio, el argumento es perfectamente utilizable respecto del ordenamiento urbanístico. Por ejemplo, es materialmente imposible revisar y rehacer a posteriori un determinado proyecto de compensación con fundamento en que se ha anulado el porcentaje de aprovechamiento que le correspondía a la Administración, porque este dato es una pieza del conjunto que está plenamente interconectada con las demás, de tal modo que no puede ser eliminada aisladamente.

3. En estrecha conexión con el último argumento citado, hay que remarcar en que le corresponde al legislador autonómico llenar los huecos que deja la Sentencia que comentamos, en aras a su «libertad de configuración normativa», por lo que la alternativa a la situación anterior no es el vacío o ausencia de regulación, sino que el legislador competente dicte su propia regulación. Este argumento había sido también utilizado por la dogmática germánica ${ }^{7}$ y recogido por nuestra jurisprudencia constitucional en la STC 45/1989: «Le cumple, pues, al legislador, a partir de esta Sentencia, llevar a cabo las modificaciones

7 Puede verse en R. Bocanegra Sierra, op. cit., pág. 528 y ss. 
o adaptaciones pertinentes en el régimen legal del impuesto, sirviéndose para ello de su propia libertad de configuración normativa, que, como hemos venido señalando, no puede ser ni desconocida ni sustituida por este Tribunal Constitucional, al que en un proceso como el que ahora concluye sólo le corresponde apreciar la conformidad o disconformidad con la Constitución de los preceptos enjuiciados».

4. Por último, y de no aceptarse esta tesis que propugnamos, se producirían unas consecuencias discriminatorias a favor de quienes no hubieran recurrido en su momento contra los actos administrativos a que nos referimos frente a aquéllos que sí lo hayan hecho y hayan obtenido sentencias denegatorias firmes, es decir, que se daría una auténtica «prima a la pasividad». El argumento ha sido también utilizado por la STC $45 / 1989$ cuando señala que «la conclusión contraria entrañaría ... un inaceptable trato de disfavor para quien recurrió, sin éxito, ante los Tribunales en contraste con el trato recibido por quien no instó en tiempo la revisión del acto de aplicación de las disposiciones hoy declaradas inconstitucionales».

La conclusión de todo lo que se acaba de decir sobre los actos firmes dictados en aplicación de preceptos anulados me parece clara. Los argumentos expuestos llevan a postular la no modificabilidad de dichos actos y su mantenimiento, a pesar de la anulación de los artículos en los que se fundamentaron. Como ya se ha visto antes, la falta de pronunciamiento al respecto por parte del Tribunal Constitucional trasladará la cuestión en última instancia a los Tribunales Contencioso-Administrativos, cuando resuelvan los posibles recursos que se planteen. Serán éstos paradójicamente quienes deberán analizar y decidir cuál es el alcance exacto de la STC que comentamos. 